\title{
Developing Module for Ethnic Interaction in Secondary School in Malaysia
}

\author{
Amir Hasan Dawi \\ Mahizer Hamzah \\ Noraini Mohamed Noh \\ Norazilawati Abdullah \\ Norwaliza Abdul Wahab \\ Sultan Idris Education University, Malaysia
}

\begin{abstract}
This paper is on developing the module for interethnic interaction in Malaysian secondary schools. The research found that students in Malaysian secondary schools have some difficulties to interact with other students from different ethnic groups. This mainly because they had attended different types of schools and culture in primary level. The formal education has separated them by the type of schools. They also practice daily activities within their own culture. Both factors have formed and strengthened their habitus of ethnicity. Hence there is a need to overcome the interethnic interaction issue in secondary schools. A research was carried out to identify the important aspects of Malaysia culture that should be understood by all students. Interview and observation were carried out to gain data from participants. The interaction module was designed accordingly with the themes. The presentation will conclude the themes that considered to be covered in the module.
\end{abstract}

Keywords: ethnicity, habitus, school, module, Malaysia

\section{Introduction}

As a country with a multi-ethnic population, the issue of inter-ethnic relations is often given attention. Indeed, it has been recognized that education in Malaysia since independence has always emphasized the aim of achieving unity among the multi-ethnic population. Education policy has developed a number of strategies to foster unity, especially in schools. However, there are many challenges in improving inter-ethnic interaction in schools. One major challenge is the existence of schools by ethnicity. The situation in Malaysia is that every individual is given the freedom of choice of schools according to their requirements. Hence there is a high likelihood that the choice of primary schools by ethnicity. There are three types of primary schools that are recognized in the national education system. These schools are generally distinguished by the medium of the language used. The schools are National School, National Chinese School and National Tamil School. Although the vernacular school system has its own advantages, there are issues behind it which in the long term can affect inter-ethnic understanding.

\section{Background}

There are three types of schools based on the language of instruction in primary schools in Malaysia. The types of schools are National School (SK), National Chinese School (SJKC) and National Tamil School (SJKT). These schools have become the first choice of every ethnic group based on the language of instruction used in the schools. To summarize, the majority ethnic Malays are in National Schools, Chinese in National Chinese Schools and Indians chose National Tamil Schools. Trends choosing schools based on ethnicity are found growing. The negative implications of this situation are the lack of effective interaction between ethnic groups when pupils are in primary schools.

Pupils who are in primary school has continued in groups of their respective ethnic communities. In these schools, habitus of ethnicity have been strengthened, either directly or indirectly. This situation is something that is actually designed by the community. Previous studies have found that the existence and continuation of SJKC and SJKT in particular are on the needs of the community itself. It was found that the existence of SJKC and SJKT are due to ethnic Chinese and Tamil need 
that type of school to guarantee the survival of their culture and mother tongue languages. In a sense, this unique situation has positive implications in terms of those ethnic communities, particularly the Chinese and Indian. But this too often raises the issue of where in the long run will affect the unity between the ethnic groups.

Pupils in primary schools are in the age range of seven to twelve years. They were separated and were in their ethnic groups themselves due to the existence of schools by ethnicity. Communication between the ethnic groups is very limited. Each ethnic group strengthens their habitus. This makes it difficult for them to interact with other ethnic communities when they are in secondary school. They brought the habits in primary school to secondary school. At the secondary school level in Malaysia, mainstream schools are National Secondary School. All students of different ethnic groups will continue their studies at National Secondary School. National Secondary School use Malay as the medium of instruction. Malay is the national language in Malaysia. Issues arise when students of different types of primary schools continue their education in secondary schools. Habitus and trajectory of ethnicity have made it difficult for them to interact with students from other ethnic groups. Generally, there are various issues between ethnic groups in secondary schools as a result of the situation prevailing in the primary.

Table 1: Compulsory Education and Type of Schools in Malaysia

\begin{tabular}{|c|c|c|c|c|}
\hline \multirow{4}{*}{$\begin{array}{l}\text { Primary School } \\
\text { (Age } 7 \text { to } 12 \text { years) }\end{array}$} & Type of School & $\begin{array}{l}\text { Medium (language) of } \\
\text { Instruction }\end{array}$ & $\begin{array}{l}\text { Expected } \\
\text { Students }\end{array}$ & Aims \\
\hline & National School (SK) & National Language & All ethnic groups & $\begin{array}{l}\text { Integration of all } \\
\text { ethnic }\end{array}$ \\
\hline & $\begin{array}{l}\text { National Chinese School } \\
\text { (SJKC) }\end{array}$ & Chinese & Chinese & $\begin{array}{l}\text { Language and } \\
\text { cultural heritage of } \\
\text { the Chinese }\end{array}$ \\
\hline & $\begin{array}{l}\text { National Tamil School } \\
\text { (SJKT) }\end{array}$ & Tamil & Indian & $\begin{array}{l}\text { Language and } \\
\text { cultural heritage of } \\
\text { the Indian }\end{array}$ \\
\hline $\begin{array}{l}\text { Secondary School } \\
\text { (Age } 13 \text { to } 17 \text { years) }\end{array}$ & $\begin{array}{l}\text { National Secondary } \\
\text { School }\end{array}$ & National Language & All ethnic groups & $\begin{array}{l}\text { Integration of all } \\
\text { ethnic }\end{array}$ \\
\hline
\end{tabular}

Table 1 shows the school system in Malaysia. Compulsory schooling started at the age of seven to twelve in the primary, and thirteen to seventeen in secondary level. As shown in the table, students have an alternative to choose between the three types of school in primary education. The different medium of instruction and cultural practices in primary school created a hurdle for them to communicate better with other ethnic when at the secondary level. Following Bourdieu's framework, the process of socialization in primary level has strengthened the habitus of ethnicity and later sharpen their trajectory of ethnicity in secondary school.

\section{Problem Statement}

Ethnic stratification in recent years seems more obvious when there is a tendency of choosing schools by ethnicity. The government's official report states:

In recent years, ethnic stratification in schools has increased. The proportion of Chinese students enrolled in SJKCs has increased from $92 \%$ in 2000 to $96 \%$ in 2011. Indian students enrolled in SJKTs have also increased from $47 \%$ to $56 \%$ of SJKT enrolment for the same period. In SKs, $97 \%$ of students are ethnically Bumiputera (mainly Malays). As student environments become more homogenous, there is a growing need for the Ministry to create avenues for students from different school-types to interact.

Malaysia Education Blueprint 2013-2025 (2013) 
Previously, studies have pointed out that efforts to improve inter-ethnic unity must be intensified in secondary schools because the majority of students will attend National Secondary School (Amir Hasan Dawi, Ikhsan Othman and Mohammad Sidik Ariffin, 2012). However, opportunities for inter-ethnic interaction in reality is not the case in most schools because not all schools have students from different ethnic composition. Thus, this study is a proactive plan to suggest methods of interaction for unity in the Malaysian secondary school. This is in line with current needs. In short inter-ethnic integration efforts must be intensified by introducing a model of interaction at the secondary school level. In developing a comprehensive module, the study will first identify inter-ethnic issues that occur when students are in secondary school.

\section{Objectives of the study}

Based on the above background, the objectives of the study are:

- To identify issues of ethnicity when students from different ethnic groups continue schooling to secondary school.

- To identify activities that can be done to improve inter-ethnic interaction at the secondary schools.

- To propose strategies to improve the interaction between different ethnic students in secondary schools.

\section{Research questions}

- What are the issues of ethnicity when students from different ethnic groups continue schooling to secondary school?

- What are the activities that can be done to improve inter-ethnic interaction at the secondary schools?

- How does the strategy to improve the interaction between different ethnic students in secondary schools?

For the purposes of this paper, the focus is on the themes in the module.

\section{Conceptual framework}

This study is a micro perspective. It is a step in the construction of activities for micro-ethnic interaction in secondary schools. The need now is to build a module that can be implemented in schools without a change in macro policy. Prior to this study, there has been no ethnic interaction module that specifically can be used in secondary schools in Malaysia. Hence, this study is an effort that gave new ideas in promoting inter-ethnic interaction for unity in secondary school.

In-depth study about the interaction between ethnic groups in national secondary schools was based on the perspective of symbolic interactionism (Mead, 1934). Social interaction begins from an individual attempts to analyse the words and actions of others against him and how he should respond to others (Blumer 1969). The micro perspective is to explain the fundamental phenomenon in society. The concept of micro sociological theory examines how a person behaves in a social setting (Stryker, 1990). Individual behaviour or actions will be interpreted and subjective behaviour will be clarified (Denzin, 1992). This perspective has two basic observations; firstly, to study the symbolic meaning or the implied meaning subjectively, and second, to see how the symbolic meaning used in human interaction. Humans do not react directly with the world around him but react to the meaning associated with it (Jenkins, 2008).

The interaction between ethnic groups at the micro level are influenced by socialization processes that have been experienced by an individual. There are three stages of the socialization process; namely the initial stage, the secondary stage, and resocialization. According to Bourdieu's habitus theory, one has the habits due to an early socialization process which is then modified by secondary socialization (Bourdieu 1998; Grenfell 2008, 2011). In the context of the interaction of primary school students in Malaysia, early socialization influenced the identity of the individual, especially when parents are empowered to determine the type of school to select at the primary level. Factors of ethnicity, culture and religion have become the determinant in choosing schools. Such early socialization has caused a rift between ethnic groups. As a result, there was the problem of interaction between ethnic groups in certain secondary school.

In terms of the theory of habitus, the interaction between ethnicity will continue to be an issue as ethnic habitus that has been embedded in the individual cannot be avoided. Bourdieu's theory can be applied to the situation prevailing in Malaysia's national secondary school when the relationship between different ethnic students said to be less satisfactory, which in turn extend into society when they complete their schooling. However, researchers believe socialization in the context of inter-ethnic interaction can be modified by performing secondary socialization and resocialization at the secondary school level. Therefore, this study theoretically sees the resocialization process in the inter-ethnic interaction that will give birth to ideas and concepts that help the formation of the nation of Malaysian. 
Overall, the study is based on understanding secondary socialization and resocialization which is fundamental to develop the interaction module. The goal is to help students to understand the importance of inter-ethnic interaction, to foster unity, to realize the negative implications of the conflict between ethnic groups as something serious and unacceptable, nurture and cultivate the love of each other, accept and respect diversity in society, to learn the skills to interact, and to stop the conflict caused by ethnic differences. The module has been constructed in accordance with the procedures as suggested by the experts (Dick, Carey \& Carey 2002). The construction of the module begins by defining goals, detailing step-by-step what students should learn, analyse existing knowledge of students, write learning objectives, and develop instructional strategies systematically.

\section{Methodology}

This study was conducted through a case study approach. This case studies involving secondary school environments which have a different ethnic composition. Instruments are interviews protocol, observations, document analysis, module construction methods and checklists. Respondents were students, teachers and administrators in the schools. The findings were used to develop a module that contains the activities involving inter-ethnic interaction. The interaction module is developed for use in secondary schools.

Case study method used in obtaining in-depth data and resolve issues through involvement in the field. This method is suitable when use in extracting real situation, thus giving birth to the new reality and the truth about the phenomena studied. Previous studies showed case studies suitable and often used in the study of ethnic relations. The researchers have already used grounded methods including ethnography and case studies in a number of studies related to social interaction. Similarly, studies of ethnic interaction in schools in developed countries such as the United Kingdom, the United States and Australia show observation and in-depth interviews have become the main method to get the data, which in turn generate new ideas to solve problems. Among the studies of the interaction between ethnic groups in the school referred to include Gillborn (1995), Tileston (2004), Portes et al (2005), Caballero et al (2007), Hall \& Hall (2008), Harris (2008), Hawley \& Nieto (2010) and Howard (2010). In summary, the findings of case studies can give an idea to solve the problem or issue being studied.

For the purposes of this paper, the analysis is based on data from the interview. Interviews were conducted with students and teachers. Information from the students is mainly related to matters that affect the interaction between different ethnic groups when they are in school. Teachers and students were also asked about information regarding the existing of interaction programs, activities, strengths, weaknesses and recommendations. Interviews with students investigate directly the causes or issues that form the pattern of interaction. Interviews with teachers and administrators identified measures that have been taken and are to be carried out for the purpose of unity.

\section{Results and discussion}

\section{The issue of interaction between students}

To discuss the issue of inter-ethnic interaction, the analysis is based on case studies in a secondary school. The population of this school is 1,613 students from various ethnic groups. The breakdown of the population by ethnic group consisted of $662(41 \%)$ of ethnic Malays, 472 (29\%) of ethnic Chinese, 361 (22\%) of ethnic Indians, and $118(8 \%)$ of other ethnic groups. Data compiled and discussed are applicable only to groups of ethnic Malays, Chinese and Indians. In-depth interviews were conducted with 10 students of the Malay, 8 Chinese, and 8 Indians. These students are in the age range of 13 and 14 years old. They have been selected based on the type of primary schools before entering secondary schools. This finding was later revised and matched with findings from interviews with school teachers. Based on the data obtained, the causes that prevent the interaction between ethnic groups in secondary schools are listed below.

- There is the issue of national language proficiency among students that affect the interaction with other ethnic groups. This is clearly among students who come from Chinese schools.

- There are students found to be very weak in the national language. Even after six years in Chinese schools, they still cannot speak the national language.

- Students who are weak in the national language will be in the same ethnic groups who speak the same native language. They will ask a friend of the same ethnicity to determine the meaning of words in the national language they do not understand. 
- Some consider the national language and English is difficult to understand because they use Chinese.

- For some students, they just meet students from other ethnic during recess. They do not have close friends from other ethnic groups.

- Students do not have friends from other ethnic because they do not get along and do not know what to talk about when they get together with other ethnic.

- Outside the school environment, which is in a residential area, the interaction between the different ethnic groups are rare.

- Students who are weak in the national language also cannot understand the students or teachers who speak fast, they like students or teachers who speak in slow tempo.

- Interaction, such a visit to a friend's house during the celebration of different ethnic festival is limited.

- Students have an interest in other cultures; such as weddings, dances, religion and so on.

- Students lack of knowledge about the comparison between cultures and religions. There was confusion about the culture, including their own ethnic culture.

- Among the causes of fights with other ethnic groups is due to using of dirty or bad words, action and name calling.

\section{The need for knowledge about other ethnic}

At this stage, observations and interviews were conducted at eight schools. A team of 32 interviewers carries out field work at the schools involved. The main objective is to identify the things that need to be known by the students in the understanding of other ethnic. Based on interviews, the information obtained from the respondents of students, teachers and school administrators have identified themes that need to be understood in improving interaction. The result of this focused activity provides insight into the understanding of the school community on the issue of ethnic interaction.

Analysis of the data shows school teachers believe that government policies and programs in schools are helping to foster unity. Education policies and plans as well as national policies are accepted as playing an important role in promoting interethnic interaction. National education policy is the foundation of unity through education. At school, the Malay language has a role as the national language, the language of unity and the language of instruction. The use of the national language by all ethnic groups is to help the interaction between ethnic and thus can form a unity.

There are a variety of programs and activities conducted in schools to create inter-ethnic interaction. However, the implementation is not encouraging, especially due to lack of consistency. Some examples of the programs are such as camping, field trips, motivational courses, cultural celebrations, festive celebrations, and community services. Sports activities are a common way in shaping the interaction between students. The annual sports activities in schools considered to be mandatory in creating interaction and harmony among students.

The curriculum also has to do with solidarity. The application of moral values in teaching is an important aspect in the success of the curriculum for unity. It is related to the awareness and capability of teachers in implementing the curriculum for interaction and unity. Implementation of good values in the syllabus should be structured according to the value of the families, communities and society. It will help the students to respect each other and understand the different ethnic groups. Understanding ethnic differences will help the interaction between ethnicity.

The data also showed an unfavourable atmosphere for interactions at schools. The situation in which students rarely get along with other ethnic is not something unusual. There was a breakdown by ethnicity. The main factors that cause the lack of interaction are due to language and cultural differences, the feeling of belonging to own ethnic groups, lack of knowledge about other ethnic, not trusting friend from other ethnic, worry in case of misunderstanding, and interests are not the same. Many respondents said that the cause of the lack of interaction between ethnicity is related to attitudes. This is because if the students themselves refuse to change, programs and activities in schools will not bring any results.

\section{Theme of the module}


The analysis concluded that the main cause of the present problems is due to language and cultural misunderstandings. Language as an important tool to communicate has become an issue when students cannot be effective in their relation with other ethnic. The language issue is in line with the failure to understand about the culture of other ethnic groups. It has caused negative attitudes, including bias and prejudice. Three themes were proposed for the ethnic interaction module, namely, culture, language and community activities. The theme of culture is seen more comprehensive and covers most of the cause of disagreements between students of different ethnicities. Cultural themes include topics such as costumes, dancing, singing, cooking, taboos, daily activities, marriage, customs, games and religion. The theme of language covers the use of language in everyday interaction and the use of polite language. Meanwhile, the theme of community programs includes family, neighbourhood and social services.

\section{Conclusion}

The school has a very important role in the formation of unity in Malaysia. But there is the issue of inter-ethnic interaction caused by different types of schools. Malaysian compulsory primary education lasts for six years, from age seven to twelve years. This six-year period is an important time of a child's development, including in terms of inter-ethnic interaction. This is followed by secondary education for five years. The question is whether schools can provide spaces for interethnic interaction? It was obvious that inter-ethnic interaction is difficult or not possible in the circumstances there were no different ethnic groups in the respective environment. This situation is contrary to the principle of nation-building in which the partnership between the ethnic groups should be the focus.

It is undeniably a specific strategy needs to be done in order to improve the interaction between ethnic groups in the schools. Strategies to improve inter-ethnic interaction is urgent in Malaysia's multi-ethnic society. However, the situation in which different ethnic students received their early education in different educational settings has affected their abilities to interact with other ethnic at the later stages. The situation in Malaysia is unique when compared with other nation states of the world where the vernacular schools only exist in Malaysia. The vernacular school system raises the issue of the selection of schools by ethnicity. But the absence of inter-ethnic interaction spaces in schools has led to a debate about the need for a vernacular school in Malaysia education system.

The issue of inter-ethnic interaction in secondary school is very important in the context of preparing future generations of Malaysia. Interaction between ethnic groups would strengthen ethnic relations (Nelson, 2005). Normally the interaction between ethnic just be easier if they share the same cultural background (Hurtado, Carter \& Sharp, 1995). The problem is the background of secondary school students who come from different types of primary schools, namely SK, SJKC and SJKT. Different schools had established strong ethnic identity. In line with the views of Hall \& Hall (2005), students of the respective ethnic feel no need for them to know colleagues from other ethnic because they have a unique identity that is able to be shared with friends of the same ethnicity.

This paper has been analysing the issue of inter-ethnic interaction that occurs in school. Different types of primary schools by ethnicity has caused difficulties for the students to interact when they are in secondary school. Interviews have identified actions that need to be done in promoting inter-ethnic interaction in secondary school. It was found that students do not have knowledge about other ethnic groups. They need information. Based on the themes, the study suggests ethnic interaction module should be introduced in secondary schools. Module produced should contain the following elements:

- Providing opportunities for students to interact and foster understanding, appreciation rights of ethnic diversity, and practice living in harmony

- Contains a variety of activities that promote communication and interaction between ethnic

- Introducing a variety of cultures and customs of other ethnic

- Applying positive values, integration and patriotism

The implementation of inter-ethnic interaction module is an intervention strategy to solve the problem of inter-ethnic relations among students. As described in this paper, each student has been confirmed by habitus of their ethnicity since in primary school. Habitus by ethnicity was then brought to national secondary schools. This situation has affected relations with other ethnic groups. Thus the activities implemented through the proposed module can also be considered as a resocialization process. In conclusion, this module will be able to enhance interaction and fostering inter-ethnic harmony. 


\section{References}

[1] Amir Hasan Dawi, Ikhsan Othman and Mohammad Sidik Ariffin. (2012). 'A Model for Strengthening National Schools Towards the Formation of a Malaysian Nation'. Journal of Teaching and Education. Vol. 1. No. 2.

[2] Blumer, H. (1969). Symbolic Interactionism: Perspective and Method. Englewood Cliffs, New Jersey: Prentice Hall.

[3] Bourdieu, P. (1998). Practical Reason: On the Theory of Action. Stanford University Press.

[4] Brewer, J. D. (2000). Ethnography. Buckingham: Open University Press.

[5] Caballero, C. Haynes, J. \& Tikly, L. (2007). 'Researching mixed race in education: perceptions, policies and practices'. Race, Ethnicity and Education. Vol. 10, No. 3, pp. 345-362.

[6] Calhoun, C., LiPuma, E. \& Postone. M. (1993). Bourdieu: Critical Perspectives. Chicago: University of Chicago Press.

[7] Denzin, N. (1992). Symbolic Interactionism and Cultural Studies: The Politics of Interpretation. Cambridge, Massachusetts: Blackwell

[8] Dick, W., Carey, L. \& Carey, J. (2002). The systematic design of instruction. (5th ed). New York: Prentice Hall.

[9] Gillborn, D. (1995). Racism and Antiracism in Real Shcools. Buckingham: Open University Press.

[10] Grenfell, M. (2011). Bourdieu, Language and Linguistics. London: Continuum.

[11] Grenfell, M. (ed) .(2008). Pierre Bourdieu: Key concepts. London: Acumen Press.

[12] Grenfell, M. (2007). Pierre Bourdieu: Education and Training. Continuum.

[13] Hall, E. T. \& Hall, M. R. (2005). The Sounds of Silence. In Down to Earth Sociology: Introductory Readings (13th Ed). New York: The Free Press.

[14] Harris III, F. (2008). 'When the Teacher is Different than Student: The Effect of Race and Ethnicity on Student Learning'. The International Journal of Learning. Vol 14, Number 10. Pg. 153- 161.

[15] Hawley, D.W. \& Nieto, S. (2010). 'Another inconvenient truth: race and ethnicity'. Educational Leadership. Vol 68, Issue 3. Pp. 66-71.

[16] Jenkins, R. (2008). Social Identity (3rd Ed). London: Routledge.

[17] Ministry of Education. (2013). Malaysia Education Blueprint 2013-2025, Preschool to Post-Secondary Education. Putrajaya: Ministry of Education Malaysia.

[18] Mead, G. H. (1934). Mind, Self and Society. Chicago: University of Chicago Press.

[19] Nelson, T. D. (2005). The Psychology of Prejudice. Harlow: Allyn and Bacon.

[20] Portes, A., Fernandez-Kelly, P. \& Haller,W. (2005). 'Segmented assimilation on the ground: the new second generation in early adulthood'. Ethnic and Racial Studies. Vol. 28, No. 6, pp. 1000-1040.

[21] Stryker, S. (1990). Symbolic Interactionism: Themes and Variations. In M. Rosenberg and R. H. Turner (eds), Social Psychology: Sociological Perspectives. New Brunswick, New Jersey: Transaction.

[22] Tileston, D.W. (2004). What Every Teacher Should Khow About Diverse Learners. London: Corwin Press. 